\title{
Economic and Sustainability Promises of Wind Energy Considering the Impacts of Climate Change and Vulnerabilities to Extreme Conditions
}

Zhang, Di ; Xu, Zhenci; Li, Canbing; Yang, Rui; Shahidehpour, Mohammad; Wu, Qiuwei; Yan, Mingyu

Published in:

The Electricity Journal

Link to article, DOI:

10.1016/j.tej.2019.05.013

Publication date:

2019

Document Version

Peer reviewed version

Link back to DTU Orbit

Citation (APA):

Zhang, D., Xu, Z., Li, C., Yang, R., Shahidehpour, M., Wu, Q., \& Yan, M. (2019). Economic and Sustainability Promises of Wind Energy Considering the Impacts of Climate Change and Vulnerabilities to Extreme Conditions. The Electricity Journal, 32(6), 7-12. https://doi.org/10.1016/j.tej.2019.05.013

\section{General rights}

Copyright and moral rights for the publications made accessible in the public portal are retained by the authors and/or other copyright owners and it is a condition of accessing publications that users recognise and abide by the legal requirements associated with these rights.

- Users may download and print one copy of any publication from the public portal for the purpose of private study or research.

- You may not further distribute the material or use it for any profit-making activity or commercial gain

- You may freely distribute the URL identifying the publication in the public portal 


\title{
Economic and Sustainability Promises of Wind Energy Considering the
}

\section{Impacts of Climate Change and Vulnerabilities to Extreme Conditions}

\author{
Di Zhanga,b, Zhenci Xuc, ${ }^{\mathrm{c},}$, Canbing Li ${ }^{\mathrm{a}, \mathrm{b}, *}$, Rui Yang, ${ }^{\mathrm{a}, \mathrm{b}}$, Mohammad Shahidehpour ${ }^{\mathrm{d}}$, Qiuwei Wu ${ }^{\mathrm{e}}$ and Mingyu Yan ${ }^{\mathrm{d}}$ \\ ${ }^{a}$ College of Electrical and Information Engineering, Hunan University, China \\ ${ }^{b}$ Key Laboratory of Intelligent Information Analysis and Integrated Optimization for Energy Internet, Hunan University, China \\ ${ }^{c}$ Center for Systems Integration and Sustainability, Department of Fisheries and Wildlife, Michigan State University, United \\ States \\ ${ }^{\mathrm{d}}$ Galvin Center for Electricity Innovation, Illinois Institute of Technology, United States \\ e Department of Electrical Engineering, Technical University of Denmark, Denmark
}

\begin{abstract}
A dramatic expansion of the worldwide wind power capacity is underway which is critical to an effective mitigation of climate change. However, wind tower infrastructure is susceptible to extreme weather conditions such as tropical cyclones and thunderstorms. Under the context of global climate changes and intense weather events, it is imperative to assess the impacts of extreme conditions on the susceptibility of the global wind power with important implications on energy security and power system resilience. In this paper, we discuss the necessity and rationality of wind power deployment considering extreme weather perspectives on enhancing the global sustainability, security, economics, and resilience. We assess the vulnerability of wind power to extreme weather events under climate change and present the correlation of wind power proliferation, extreme weather events, and climate change issues. Our results indicate that, if extreme wind speed increases by $20 \%$ considering a 50 -year return wind speed and load safety factor is changed from 1.35 to 1.7 , the initial capital cost of wind unit installation by the end of this century could increase by about $12 \%$ because of the higher strength in tropical cyclones. In this period, upward lightning strike will be intensified due to the use of taller wind turbines and higher angular speed of blades. Also, additional storm surges and sea ices will potentially cause higher risks to inland and offshore wind tower structures and foundations because of the continuously rising sea levels. It is confirmed in our discussion that the proliferation of wind power generation would be beneficial despite its vulnerabilities by curbing the use of fossil-based power generation units, mitigating severe carbon emission, and reducing climatic changes and extreme weather events, which could also cause significant structural damages to wind turbines installations globally. The article concludes that it is vital in the scientific community to further analyze the relationship among global wind energy integration, extreme weather events, and climate changes, and for politicians to formulate a comprehensive energy policy strategy, as engineers continue to investigate the means of deploying additional inland and offshore wind farms and consider other types of renewable energy resources with a direct link with weather conditions, for a sustainable, economic, secure, and resilient energy production.
\end{abstract}

\section{Keywords: Wind energy, Sustainability, Extreme weather}

\section{Introduction}

Carbon dioxide $\left(\mathrm{CO}_{2}\right)$ emission produced by electricity generation is the dominant cause of the anthropogenic climate change Error! Reference source not found., accounting for about $40 \%$ of energy-related $\mathrm{CO}_{2}$ emissions in 2016 Error! Reference source not found. Although the number is changing because of the retirement of a large number of coal power plant, there is a global agreement among stakeholders that it is imperative to restrain climate changes by limiting average temperature increase to below 2 degree Celsius $\left({ }^{\circ} \mathrm{C}\right)$ above the pre-industrial level and pursuing additional efforts to limit the warming to $1.5^{\circ} \mathrm{C}$. To attain this goal, the Intergovernmental Panel on Climate Change (IPCC) report pointed out that the global greenhouse gas (GHG) emission would need to be decreased by $45 \%$ from 2010 levels by the year 
2030 [3]. It is generally acknowledged by experts that the stated goal can be achieved by increasing the integration of renewable energy resources.

In recent years, the proliferation of RES, including hydropower, solar power, geothermal, and wind power, has begun to play an increasingly important role in achieving climate change goals. As kinetic energy in the atmospheric boundary layer exceeds the present world electricity demand [4], large wind turbines convert the kinetic energy into electricity. Wind power has experienced a remarkably rapid expansion in recent years as the global installation of wind generation capacity has increased by nearly 80 times from 7.5 gigawatts (GW) in 1997 to almost 600GW in 2018 [5]. The steady increase of the global annual wind energy growth rate from 2011 to 2018 was about $17 \%$ ranking second only to hydropower [5]. According to the analyses provided by the International Renewable Energy Agency (IRENA), as the growth in offshore wind power is expected to increase by more than $650 \%$ in 2030 , wind power will be exceedingly viewed a key power generation technology in a decarbonized global economy [5].

However, wind power generation is vulnerable to extreme weather conditions. GHG emission causes global warming, which will increase the earth field energy. Accordingly, the Coulomb force between charges will form a rift on the land surface, which at a macro level is shown as the tension of continental plate producing elastic potential energy. The energy release in this case often appears as extreme weather with destructive consequences on human activities. The examples include tropical cyclones, which pose significant threats to populations and constructions in coastal zones [8]. The intensity of global tropical cyclone has become stronger which includes increasing sea surface temperature (SST) since mid 1970s [9]. Similarly, lightning strikes during a thunderstorm, which is the most underrated hazard, can claim dozens of lives, destroy infrastructures and cause blackouts in many regions globally [10]. In essence, the deployment of large wind turbines in such conditions is highly susceptible to weather conditions, while the frequency and intensity of extreme weather events are projected to heighten in the context of global climate changes. Some researchers have explored and analyzed the impacts of intense climate changes on the proliferation of wind power generation. Earlier studies identified multiple scenarios in various regions, where wind power generation is expected to grow, with concluding results which represented high uncertainty and lack of consistency among climate models [11]. To solve this problem, Johnson et al focused on wind power generation density as a measure of available wind power generation in the continental United States [12]. Related research also included that of Fant et al which developed a risk-based assessment of climate change impacts on wind and solar energy resources, considering the uncertainty in atmospheric carbon emission level and changes in global climate levels [13].

In practice, the impact of extreme weather events such as tropical cyclones and thunderstorm on wind power generation has attracted the attention of several investigators with controversial outcomes. In such cases, it continues to be extremely critical to assess the effect of climate changes on wind power generation and identify difficulties in utilizing wind power generation if climate changes persist with devastating regional results (hurricanes, disappearance of glaciers, extensive flood levels, large droughts, and massive regional fires). Hence, it is vital in the scientific community to urgently analyze the relationship among wind power generation, extreme weather events, and climate changes, and for politicians to formulate a comprehensive energy policy, as engineers deploy additional wind farms and other types of renewable energy resources which depend on climatic changes and resources for energy production. In this article, we focus our attention on the impacts of tropical cyclones and thunderstorms in regions where climate changes have had significant effects on wind turbines structure and the vulnerability of wind power generation. Accordingly, we consider a correlation among wind energy, extreme weather and global climate change where construction and O\&M costs of wind farm is analyzed in extreme weather events. In addition, influences of other extreme weather events, including storm surge and extreme minimum temperature alternations, on wind power are analyzed. Based on analyses of the impact of extreme weather events on wind power generation, this paper some specific technological and policy implications for the deployment of additional wind power generation units as a means of alleviating energy crises and climate changes proposes. 


\section{Effects of tropical cyclones on operational security and investment viability of offshore wind farms}

Owing to the short span and the quality of historically collected data, lack of strong variability in climate conditions, and partial understanding of driving forces in extreme events, there remains to be a significant challenge in detecting the links between human-induced climate changes and trends in tropical cyclone activities. Many researchers are devoted to studying such relations. The CO2-induced tropical warming of SST is considered as one of the conditions for the formation of tropical cyclones [14]; however, there is also an argument as to whether the local SST or the incremental difference between the local SST and the mean tropical SST has a more profound influence on tropical cyclones [15]. Based on existing simulations with high-resolution dynamical models, global tropical cyclones are consistently projected to have $2-11 \%$ higher intensities by the end of the 21 st century with higher annual frequencies in the background of greenhouse warming [16]. Moreover, the power dissipation of hurricanes is inversely correlated with the increasing SST suggesting an upward trend in destructive potentials [14].

Tropical cyclones primarily affect offshore wind farms. By the end of 2017 , nearly $84 \%(15,780 \mathrm{MW})$ of all offshore wind energy installations were located in eleven European countries with the remaining installations located mainly in China, Vietnam, Japan, South Korea and the United States [18]. The tropical cyclones affecting wind turbines are divided into three categories including the utilizable, defense-required, and destructive [19]. North Pacific and North Atlantic regions have recorded the most prolific tropical cyclone basins, with an upward trend in the regional intensity of such events [17]. The predicted higher-intensity tropical cyclones can lead to a greater probability for destructive cyclones in upcoming years, which can result in additional damages to existing wind farms and tower structures, and hinder the development of additional offshore wind power units. The result is that fewer off-shore sites will be available to ensure stable, sustainable, and economic operations of electricity grid, despite the projected continuity of abundant wind resources in these basins.

One key design criterion for wind turbines is the regional wind pattern that governs the deployment of wind turbines [20]. In Table 1 we list the International Electrotechnical Commission (IEC) categories and the corresponding wind speed for turbine design. Blades in high wind sites and low wind sites have different designs to optimize performance. Turbines in lower wind speed locations at a given rated power will need a larger rotor to capture the same amount of energy as a similar turbine. The milder wind climate makes it possible for the turbine structure to carry a larger rotor, and thus an efficient turbine can be designed. Even so, the cost of energy will always be lower for wind power at sites with a higher average wind speed. Concerning the cyclones, the $\mathrm{U}_{50}$ index, defined as the 10-minute sustained extreme wind speed with a 50-year return period is a possibility for design criterion. Return period is the inverse of the average frequency of occurrence of wind speed. In this case, 50-year return period indicates that there is a $(1 / 50$ or $2 \%)$ chance that 10-minute sustained wind speed in any year will exceed the designated $U_{50}$ index. In Table 1 , we list two indices for cyclones. One is the IEC 50-year return wind turbine class which is associated with the $\mathrm{U}_{50}$ index. The other is the SaffirSimpson Hurricane Wind Scale (SSHWS) which is based on 1-minute sustained extreme wind speed. The former can be transformed to the SSHWS index by a conversion factor of 1.11 [21]. Since the intensity of tropical cyclones shows an upward trend and increasing extreme weather events are projected to exceed existing design standards, both indices indicate that future designs may need to be enhanced accordingly to consider the storms more exclusively, especially for offshore wind farms in the areas prone to cyclones. Another key design criterion is safety factor (i.e., ratio of turbine material's strength to an expected strain) in which a larger safety factor will provide higher reliability in design. The improved design requirement can be met by a higher return period in the loading design (i.e., increase the return period of extreme storms from 50 to 100 years), a larger safety factor in the strength design criteria, or a combination of the two solutions [22]. Consequently, the capital cost of offshore wind farm may increase because of higher design standards for installations in harsher environments. A typical capital cost breakdown of offshore wind power generation system is 
Table 1 Comparison of IEC and SSHWS Indices

\begin{tabular}{|c|c|c|c|}
\hline Hurricane Category & IEC Wind Speed $(\mathrm{m} / \mathrm{s})$ & IEC 50-Year Return Wind Speed $(\mathrm{m} / \mathrm{s})$ & SSHWS $(\mathrm{m} / \mathrm{s})$ \\
\hline 1 & 37.5 & 52.5 & $33-42$ \\
\hline 2 & 42.5 & 59.5 & $43-49$ \\
\hline 3 & 50 & 70 & $50-58$ \\
\hline 4 & - & - & $58-70$ \\
\hline 5 & - & - & Larger than 70 \\
\hline
\end{tabular}

Table 2 Capital cost breakdown for typical offshore wind power systems.

\begin{tabular}{|c|c|}
\hline Item & Percentage Cost \\
\hline Wind turbine & 40 \\
\hline Grid connection & 15 \\
\hline Construction & 20 \\
\hline Other capital & 25 \\
\hline
\end{tabular}

An estimate of the change of the capital cost in relation to a higher design requirement is provided in [24]. The extreme loading costs are assumed to be proportional to the normal loading costs, which is proportional to the square of mean wind speed and directly proportional to load factors. About half of tower and foundation construction costs are driven by extreme loading of wind turbines [24]. For a wind turbine, tower costs account for a quarter of the total costs, and the rotor and nacelle account for the other three quarters [25]. The rotor-nacelle-assembly design is assumed to be driven by fatigue, which may be debatable for installations in typhoon-prone regions. According to the percentages given in Table 2, the grid connection and other capitals contribute to $40 \%$ of the total costs. The changes in grid connection and other capital cost are disregarded in the present model. Hence, the relative changes in total $\operatorname{cost} C / C_{r e f}$ due to changes in extreme wind speed is expressed as [24],

$$
\frac{C}{C_{r e f}}=\underbrace{\frac{2}{5}[\frac{3}{4}+\overbrace{\frac{1}{4}\left(\frac{1}{2}+\frac{1}{2} \frac{\gamma_{f}}{\gamma_{f, r e f}} \frac{U^{2}}{U_{r e f}^{2}}\right)}^{\text {Tower }}}_{\text {Wind turbine }}+\underbrace{\frac{1}{5}\left(\frac{1}{2}+\frac{1}{2} \frac{\gamma_{f}}{\gamma_{f, r e f}} \frac{U^{2}}{U_{r e f}^{2}}\right)}_{\text {Construction }}+\frac{2}{5}=\frac{17}{20}+\frac{3}{20} \frac{\gamma_{f}}{\gamma_{f, r e f}} \frac{U^{2}}{U_{r e f}^{2}}
$$

where $\gamma_{f, r e f}$ and $U_{r e f}$ denote the reference safety factor and reference extreme wind speed (i.e., 50 -year reference wind speed) respectively, and $\gamma_{f}$ and $U$ are load safety factor and extreme wind speed respectively in tropical cyclone areas. To maintain the same level of reliability considering the impacts of tropical cyclones, $\gamma_{f, r e f}$ is recommended to be 1.35 in Europe and North America [26]. Storm intensity is expected to increase by about $20 \%$ near the eye of the storm and the intensity is expected to increase by $10 \%$ by the end of this century [27]. If the extreme wind speed increases from $\mathrm{U}_{50}$ by $20 \%$ because of the change in tropical cyclone intensity, the safety factor could be adjusted to about 1.7 , and the corresponding capital cost could be increased by about $12 \%$.

\section{Risk of lightning strikes on wind turbine operations}

Lightning strikes are considerable threats to wind turbines, as significant portion of strikes terminate on blades and flow through the structure to ground. Exposed wind turbines which are taller than adjacent objects provide an excellent means of propagating lightning charges [31]. The lightnings which strike wind turbines are shown in Fig. 1. In lightning incidents, turbine blades are the most vulnerable components, which are made of composite materials that are sensitive to electric discharges and lightning. More than half of lightning faults occur in wind turbine control systems, with critical 
impacts on wind turbine operations [32].

According to the Forth Assessment Report (AR4) of IPCC, there is an insufficient evidence to conclude a linkage between lightning and global climate change [2]. As remote sensing offers a potential alterative to detect changes in small-scale severe weather such as satellite proxy measurements of lightning, projection studies have been conducted on lightning activity variations. According to experimental and modeling results, the lightning activity is projected to increase in hot and dry climates, because thunderstorms are more explosive when there are fewer rainfalls [28]. Regionally, lightning is associated with not only the surface temperature and humidity, but also aerosol loading. In recent years, this potential energy tends to increase as the climate changes to be warmer and clear trends show an increase in cloud-to-ground lightning strikes in many regions of the world as presented in [29].

The risk of lightning strikes at wind turbines is a function of wind turbine height, local terrain and wind farm topography, and regional lightning level [20]. Modern wind turbines are characterized by taller towers and longer blades, because higher-altitude wind usually means a higher power density. The height of the structure has far exceeded $100 \mathrm{~m}$ (tower plus blade), which are more exposed to lightning strikes. Moreover, in recent years, an increasing number of upward lightning strikes emitted by wind turbines has been recorded in which the height and the movement are two major causes. Also, rapid rotation of blade tips plays an important role in this type of discharge because rotating wind turbines are more likely to cause lightning than static objects [33]. Therefore, modern wind turbines may be easily stricken by lightning, and most of the strikes are expected to be upward lightning as the percentage increases with the height of the turbine structure, regardless of the trend in lightning activities.

Although the number of lightnings striking wind turbines grows in taller wind structures and rapid blade tip movements, further studies are needed to find accurate relations among changes in extreme climatic conditions, physical characteristics of wind farm infrastructures, and correlations among corresponding risks.

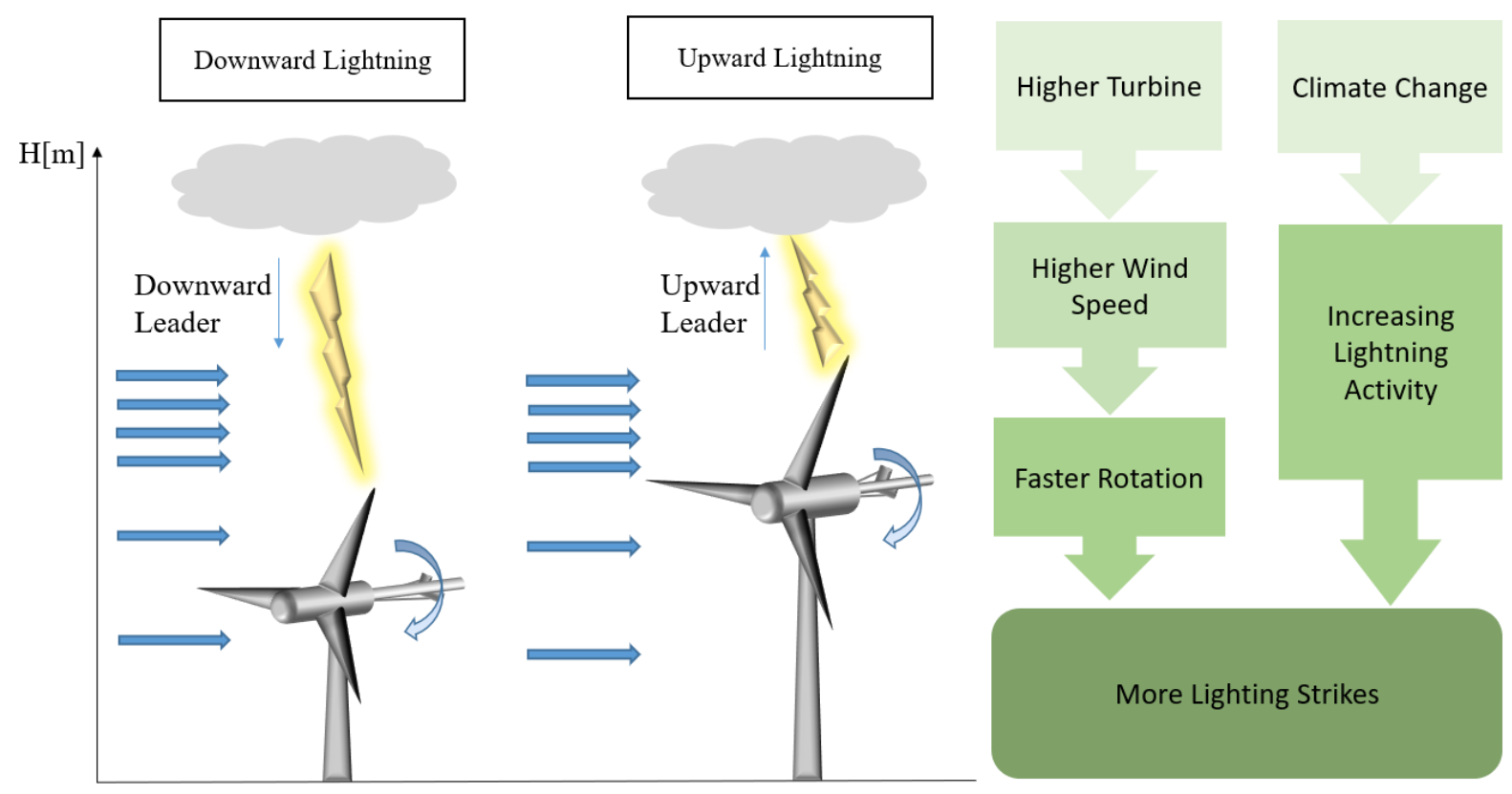

Figure 1 Types of lightning strikes to wind turbines

\section{Impacts of other extreme weather events on the operation and maintenance of wind farms}

Other extreme weather events such as storm surges and extreme minimum temperatures could also be heightened with an increase in global temperature. Hence, the impacts of these phenomena on the installation and the operation and maintenance (O\&M) of wind turbines would also need to be considered. Storm surges are abnormal water rises connected with low pressure systems which are the most fatal and destructive secondary hazards of cyclones. The storm 
surge magnitude is determined by storm characteristics and the coastal geometry and bathymetry. Consequently, storm surge changes cannot be directly inferred by analyzing the changes in a single storm characteristic. Hence, it is not currently possible to accurately assess storm surge variations stemming from climate changes, or to quantify the impacts of projected storm surges at regional scales due to uncertainties associated with tropical and extratropical cyclones [34].

However, according to the IPCC15 records and other prediction models, the poleward shift of extratropical cyclones has an upward trend, which, together with future sea-level rises exacerbated by adverse weather conditions [16], will culminate in additional vulnerabilities of wind turbines in coastal areas. Storm surges do damage to offshore wind turbine towers and foundations, inducing a collision and causing severe vibrations in offshore structures. Although there is an inconsistent projections of storm surge intensities due to the rising global temperature, it is generally expected that the storm surge frequency will increase in some basins. The additional storm surges pose more risks not only to wind turbine towers but also seabed structures and cables in wind farms. Frequent occurrences of such events could cause the seafloor sediment to be more mobile than previously anticipated, and corresponding scour and sand wave migrations would likely cause more cable exposures, while replacing the cables is expensive and difficult in most offshore locations [35].

Extreme minimum temperatures could inevitably change owing to higher global temperatures. Consequently, the formation of variable sea ice in many regions is conceivable, including offshore wind farm. Sea ice, particularly the drifting sea ice, could form multiple pieces of ice floes which are moved around by intense winds. In addition, pack ice formed on the ocean surface can exceed $1 \mathrm{~m} / \mathrm{s}$ drift speed [36]. The annual mean Arctic sea-ice extent declined from 3.5 to $4.1 \%$ per decade from 1979 to 2012 . Although the situation is reversed in the Antarctic region, there are strong local differences as well. Furthermore, researchers have projected reductions in the Baltic Sea mean total ice thickness, sea ice extent, and sea ice days, with some areas becoming ice-free because of climate changes [35],[36]. The sea ice loading (i.e., ice buildup on the tower) is the main component of the offshore wind turbine loading, which mainly includes static winter ice load, winter block ice impact, and drifting ice dynamic impact. Climate change analyses of sea ice predicts a reduction in the future sea ice loading, which may mean sites considered previously as unsuitable for offshore wind farms would be available in the future, which benefit the wind energy deployment. However, vicious cycle of sea-level rise and global warming, resulted from the melting of sea ice, indicate that although the reduction in extreme minimum temperature would benefit the wind energy development under extreme climate changes, the benefits are far less than potentially increasing risks in forthcoming decades. The drifting ice, a large projected reduction in sea ice scale formed in the 21 st century, potentially increases turbine wave loading, induces collisions with wind turbine tower and foundation, and leads to enormous impacts on offshore structures [35].

\section{Technological implications}

As a mainstream renewable power generation, wind energy can help reduce carbon emissions and contribute to less human-induced global climate changes. Considering that the renewable electricity generation could play an increasingly important role in greenhouse gas emission mitigation and the limitation of climate change risks, the installed wind capacity has increased by orders of magnitude in various regions of the world during the last two decades. Wind power generation is climate sensitive and wind turbines are vulnerable to extreme weather events. Accordingly, the rising numbers of extreme weather events which are mainly influenced by human-induced global climate changes, will have negative effects on wind power generation. In turn, fewer extreme weather events could reduce potential damages to wind turbine structures and O\&M costs of wind farms.

In order to cope with the impact of extreme weather events on wind power generation, we should consider technological characteristics of wind farms as well as regional climatic conditions that contribute to renewable power generation portfolio for supplying electricity loads. The technological characteristics that need be considered include the type and the capacity of wind generators, tower height, tower foundation strength, blade type, gearbox, load pattern, and the grid connection. Other technological implications for adapting to extreme weather events are presented below 
according to the discussions presented in this paper. First, changing the orientation of wind turbines could be beneficial in optimizing the wind farm resilience and structural efficiency against climatic conditions. Second, because of the upward leader phenomenon occurring frequently in lightning strikes, the lightning protection system needs to be designed effectively in order to handle upward and downward leaders. Third, the development of anti-shock towers and tower foundation materials are critical for offshore wind turbines in order to be responsive to sea ice and storm surge. Fourth, wind farms could be used in power-to-gas (electrolytic hydrogen technology) and energy storage technologies in order to convert the electricity generated by wind farms to other types of energy. In the case of wind farm outages in extreme weather conditions, the proposed energy conversion technologies can reduce the impact of wind farm outages on power system capacity efficiency.

\section{Socioeconomic and and regulatory implications}

Wind power is pollution-free. The capacity and the distribution of wind power generation in each region is limited by local climatic conditions, but the irreplaceable role of wind power generation as a clean energy source in reducing carbon emissions is unquestionable. In addition, wind energy industry brings to each region billions of dollars in private investment and thousands of well-paying new jobs. A dynamic investment venture and corresponding employments will also increase the government's tax revenue and the regional socioeconomic stability. Based on the analysis of the global wind energy vulnerability to extreme weather events, specific policies are considered for wind energy deployment which are discussed as follows:

i) Extreme weather events which happen frequently with higher intensities necessitate more specific and directed technical standards for managing the wind turbine design, construction, operation, and maintenance. Accordingly, existing standards which are formulated by IEC and other participating organizations would need to be updated in a timely manner. In addition, administrative requirements for the approval of wind power generation enterprises should be kept at minimum. Although socioeconomic and ecological prospects of wind power generation can promote the investment on renewable energy in different regions, existing regulatory constraints, which are occasionally driven by large power utilities are not utterly conducive to such private investments. Therefore, market options and government incentives for promoting the investment on wind power generation should be stepped up more aggressively to create a fair, viable, and open environment for promoting renewable energy portfolios.

ii) As local and federal governments pay more attention to regulatory and environmental aspects of promoting noncarbon power generation, capital investments and operation costs of such projects will continue to look more attractive to individual stakeholders. According to our discussions, without considering the impact of extreme weather, offshore wind power generation will offer better economics than those located inland. However, installation requirements and operational reliability mandates for wind turbines, operation and maintenance requirements, transmission and delivery of energy, and sea weather conditions, will increase the cost of offshore wind farms when the prospects for extreme weather events are more significant. Therefore, there should be a concerted global effort to limit the relevant project development costs in order to be able to utilize abundant inland and offshore wind power generation resources throughout the world.

iii) The role of wind power generation in sustaining the energy security should be further emphasized along with the challenges of climate change and environmental concerns. The review of any regional energy infrastructure investment must consider the critical impacts of resilience and adaptability provided by distributed energy resources. Any withdrawal from international agreements on clean energy deployments such as the Paris Agreement [37], could further promote the use of carbon-based energy technologies in developed and developing countries, delay the deployment of off-grid and distributed energy resources in impoverished and economically disadvantaged nations, discourage the promotion of research and development on affordable wind power generation technologies and new discoveries in renewable energy-based microgrid deployments in accordance with discussions presented in this paper. Therefore, while the cooperation on mitigating climate change should continue, industrial countries should strengthen 
international relations on finding affordable ways of achieving the dual objectives of enhancing energy security and climate security.

\section{Conclusions}

In this paper, the positive influence relationship among wind power, extreme weather and climate change is discovered. From an energy security and economic point of view, impacts of several kinds of extreme weather events on wind turbines vulnerability along with global climate changing is assessed. The interactions among wind energy, electricity generation portfolio, and climate change along with negative impacts of extreme weather events are studied. In the areas prone to tropical cyclones, more frequent high-intensity tropical cyclones may result in fewer suitable sites and higher costs of installation and O\&M for offshore wind farms, even if there are high-quality wind resources. By the end of this century, if extreme wind speed increases simultaneously by $20 \%$ from the 50 -year wind speed $\mathrm{U}_{50}$, with load safety factor changed from 1.35 to about 1.7 , consequently the initial capital costs could increase approximately by $12.2 \%$ because of the intensity change of tropical cyclones. The changing trend of lightning activities is undetected under climate change according to the IPCC, however, it has been projected to increase in many regions. Additionally, the increasing height of wind turbine and fast rotation of blades play key roles in initiating upward lightning strikes. Although storm surges, the secondary hazards of cyclones cannot be projected by the changes with the storm characteristic alterations, they are also likely to cause more risks to wind turbine towers and foundations in some coastal areas because of the continuously rising sea-level. The variation of sea ice potentially increases turbine wave loading, induces a collision against the wind turbine tower and foundation, and has an adverse effect on offshore structures.

The development of wind power is a key solution to cope with climate change. Climate change will be more likely to result in high frequency and intensity of extreme weather events, which has negative effects on wind power generation. According to the discussion in this paper, wind power is under the situation of increasingly urgent development.

\section{References}

[1] Ban, M., Yu, J., Shahidehpour, M., Guo, D., Yao, Y. Considering the differentiating health impacts of fuel emissions in optimal generation scheduling, IEEE Tran. Sustain Energy, 2019

[2] UNFCC Paris Agreement (United Nations, 2015)

[3] IPCC Global warming of $1.5^{\circ} \mathrm{C}$ (eds Masson-Delmotte, V. et al) (Cambridge Univ. Press, 2018)

[4] Barthelmie, R. J. and Pryor, S. C. Potential contribution of wind energy to climate change mitigation. Nat. Clim. Change4,684688 (2014).

[5] World wind market has reached 486 GW from where 54 GW has been installed last year (World Wind Energy Association, 2017); http://www.wwindea.org/11961-2/.

[6] Wind power, Renewable Energy Technologies: cost analysis series 2012 (International Renewable Energy Agency, 2012).

[7] Sengupta, D. and Bureau, E.T. Falling Costs and Tech Innovations Will Drive Offshore Wind Power Boom. The Economic Times. http://trove.nla.gov.au/work/215360024?q\&versionId=236390706.

[8] IPCC Managing the Risks of Extreme Events and Disasters to Advance Climate Change Adaptation (eds Field, C. B. et al.) (Cambridge Univ. Press, 2012).

[9] Elsner, J. B., Kossin, J. P. and Jagger, T. H. The increasing intensity of the strongest tropical cyclones. Nature455, 92-95 (2008).

[10] Thunderstruck: Lightning Will Increase with Warming. available at http://www.climatecentral.org/news/lightning-strikes-willincrease-with-warming-18323.

[11] Pryor S.C. and Barthelmie R.J., Climate change impacts on wind energy: A review. Renew. Sust. Energ. Rev. 14, 430-437 (2010).

[12] Johnson D. L. and Erhardt R. J., Projected impacts of climate change on wind energy density in the United States. Renew. Energ. 85, 66-73(2016).

[13] Fant C., et al. The impact of climate change on wind and solar resources in southern Africa. Appl. Energy 161, 556-564(2016).

[14] Emanuel, K. Increasing destructiveness of tropical cyclones over the past 30 years. Nature436, 686-688 (2005).

[15] Ramsay, H. A. and Sobel, A. H. The effects of relative and absolute sea surface temperature on tropical cyclone potential intensity using a single column model. J. Clim.24, 183-193 (2011).

[16] Knutson, T. R. et al. Tropical cyclones and climate change. Nat. Geosci. 3, 157-163 (2010).

[17] Mendelsohn, N. et al. The impact of climate change on global tropical cyclone damage. Nat. Clim. Change2, 205-209 (2012).

[18] GWEC Global Wind 2017 Report: Offshore Wind Power. http:/gwec.net/global-figures/global-offshore/. 
[19] Feasibility study of the impact of typhoon on offshore wind farm operation in China, report no. EEPPMU/CN/12607/RE003(2009).

[20] Veritas, D. N. Guidelines for design of wind turbines. Campus Risø, (2002).

[21] Sirnivas, S., Musial, W., Bailey, B. and Filippelli, M. Assessment of Offshore Wind System Design, Safety, and Operation Standards. National Renewable Energy.

[22] Design Standards for Offshore Wind Farms- Project. American Bureau of Shipping, report no. 670(2011)

[23] Ports, P. D. Offshore Wind Project Cost Outlook. (Clean Energy Pipeline, 2014).

[24] Clausen, N. E. Design of Wind Turbines in Typhoon area. (ASEAN Wind 2005 EU Project, 2006).

[25] Renewable Energy Cost Analysis: Wind Power (International Renewable Energy Agency, 2012).

[26] Clausen, N., et al. Wind farms in regions exposed to tropical cyclones. (Germanischer Lloyd Wind Energie GmbH, Hamburg) European Wind Energy Conference and Exhibition (2007).

[27] Bradford, N. Increased Hurricane Intensity. available at https://www.neefusa.org/nature/water/increased-hurricane-intensity.

[28] Price C. Will a drier climate result in more lightning? Atmos. Res. 91, 479-484 (2009).

[29] Pawar, S. D., Lai, D. M. and Murugavel, P. Lightning characteristics over central India during Indian summer monsoon. Atmos. Res. 106, 44-49 (2011).

[30] Romps, D. M., Seeley, J. T., Vollaro, D. and Molinari, J. Projected increase in lightning strikes in the United States due to global warming. Science346, 851-854 (2014).

[31] Rodrigues, R. B.et al. An investigation over the lightning location system in Portugal for wind turbine protection development Power and Energy Society General Meeting, IEEE, 1-8 (2008).

[32] IEC. Wind turbine generator system-part 24: lightning protection. TR 61400-24. (2002).

[33] Montanyà, J., Van der Velde, O. A. and Williams, E. Turbines shoot upside-down lightning. Nature506, 268 (2014).

[34] Lin, N., Emanuel, K., Oppenheimer, M. and Vanmarcke, E. Physically based assessment of hurricane surge threat under climate change. Nat. Clim. Change 2, 462-467 (2012).

[35] Pryor, S. C. and Barthelmie, R. J. Assessing the vulnerability of wind energy to climate change and extreme events. Climatic change 121, 79-91 (2013).

[36] Meier, HEM., Deier, R. and Halkka, A. Simulated distributions of Baltic Sea-ice in warming climate and consequences for the winter habitat of the Baltic ringed seal. Ambio33, 249-56 (2004).

[37] Statement by President Trump on the Paris Climate Accord. available at https://www.whitehouse.gov/briefingsstatements/statement-president-trump-paris-climate-accord/.

Di Zhang received her B.E. degree in electric engineering and automation from Henan Normal University, Xinxiang, China, in 2014. She is currently pursuing her Ph.D. degree in electrical engineering at Hunan University, Changsha, China. She is a visiting PhD student at the Robert W. Galvin Center for Electricity Innovation at Illinois institute of technology. Her major research interests include power system operation and control, energy policy and cyber security for smart grid.

Zhenci Xu received his B.E. degree in Irrigation and Drainage Engineering from China Agricultural University, Beijing, China, in 2014. He is a PhD student at the Center for Systems Integration and Sustainability at Michigan State University. His research interest is sustainability science, focusing on integrating techniques from multiple disciplines (e.g., environmental economics, and system modeling) to study complex effects of telecoupling processes on the coupled human and natural systems cross multi-scale.

Canbing Li received his B.Sc. and Ph.D. degrees in electrical engineering from Tsinghua University, Beijing, China, in 2001 and 2006, respectively. He is currently a Professor with the College of Electrical and Information Engineering, Hunan University, Changsha, China. His research interests include smart grid, energy efficiency, and energy policy.

Rui Yang received her B.Sc. degree in electrical engineering from Central South University, Changsha, China, in 2015. She is currently pursuing the M.S. degree at the College of Electrical and Information Engineering in Hunan University, Changsha, China. Her major research interests include power system dispatch and power markets.

Mohammad Shahidehpour received his Honorary Doctorate degree from the Polytechnic University of Bucharest, Bucharest, Romania. He is a University Distinguished Professor, and Bodine Chair Professor and Director of the Robert W. Galvin Center for Electricity Innovation at Illinois Institute of Technology. He is a member of the US National Academy of Engineering, Fellow of IEEE, Fellow of the American Association for the Advancement of Science (AAAS), and Fellow of the National Academy of Inventors (NAI).

Qiuwei Wu received his B.Eng. and M.Eng. degrees in power system and its automation from the Nanjing University of Science and Technology, Nanjing, China, in 2000 and 2003, respectively, and his Ph.D. degree in power system engineering from Nanyang Technological University, Singapore, in 2009. He has been with the Department of Electrical Engineering, Technical University of 
Denmark, since 2009, where he held a post-doctoral position from 2009 to 2010, was an Assistant Professor from 2010 to 2013 , and has been an Associate Professor since 2013. His research area is power system operation and control with high renewables, including wind power modeling and control, active distribution networks, and integrated energy systems.

Mingyu Yan received his B.S. degree from the College of Electrical Engineering, Zhejiang University, Hangzhou, China, in 2016 and completed his master's degree in Huazhong University of Science and Technology, Wuhan, China in 2018. He is a PhD student at the Robert W. Galvin Center for Electricity Innovation at Illinois Institute of Technology. His research interests include power system operation and planning, multiple energy system integration, and power system reliability. 